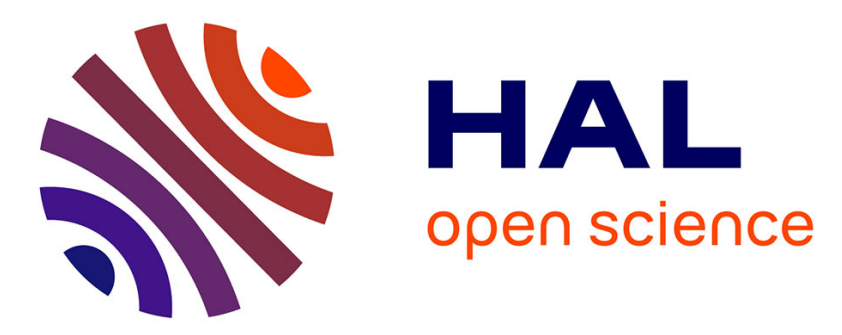

\title{
Food rejections in children: Cognitive and social/environmental factors involved in food neophobia and picky/fussy eating behavior.
}

\author{
Jérémie Lafraire, Camille Rioux, Agnès Giboreau, Delphine Picard
}

\section{- To cite this version:}

Jérémie Lafraire, Camille Rioux, Agnès Giboreau, Delphine Picard. Food rejections in children: Cognitive and social/environmental factors involved in food neophobia and picky/fussy eating behavior.. Appetite, 2016, 96, pp.347-357. 10.1016/j.appet.2015.09.008 . hal-01464651

\section{HAL Id: hal-01464651 \\ https://hal.science/hal-01464651}

Submitted on 17 May 2018

HAL is a multi-disciplinary open access archive for the deposit and dissemination of scientific research documents, whether they are published or not. The documents may come from teaching and research institutions in France or abroad, or from public or private research centers.
L'archive ouverte pluridisciplinaire HAL, est destinée au dépôt et à la diffusion de documents scientifiques de niveau recherche, publiés ou non, émanant des établissements d'enseignement et de recherche français ou étrangers, des laboratoires publics ou privés. 
1 Food rejections in children: Cognitive and social/environmental

2 factors involved in food neophobia and picky/fussy eating behavior

3

4 Jérémie Lafraire ${ }^{\mathrm{a}}$, Camille Rioux ${ }^{\mathrm{a}, \mathrm{b}}$, Agnès Giboreau ${ }^{\mathrm{a}}$, Delphine Picard ${ }^{\mathrm{b}}$

5

6 a Center for Food and Hospitality Research, Paul Bocuse Institute, 69130, Ecully, France

7 b Aix Marseille University, PSYCLE EA3273, 13621, Aix en Provence, France 8

9 Abstract

10

11 Food neophobia and picky/fussy eating behavior are presented as the two main forms of

12 children's food rejections responsible for a reduction of their dietary repertoire. We review

13 the key factors, presented in the literature, that are involved in food rejections during

14 childhood. We first consider a range of "cognitive factors", such as food perception, mental

15 representations, categorization of food items, and emotions and feelings toward food. We then

16 focus on "social and environmental factors", as these might also significantly influence and

17 modulate children's food rejections. We then summarize the findings to provide a

18 comprehensive view of the factors involved in children's food rejections. Finally, we discuss

19 the need for future studies on food rejections, regarding (i) the distinction between food

20 neophobia and picky/fussy eating, and (ii) the potential link between food categorization

21 abilities and children's food neophobia and pickiness.

23 Keywords: Children; Food rejection; Food neophobia; "Picky/fussy" eating; Cognitive and 24 social factors. 
Introduction

31 Food neophobia and picky/fussy eating behavior in children

32

Definitions

33

Assessment of measures

34

Developmental trends

Cognitive factors involved in children's food rejections

Food perception mechanisms

Mental representations and categorization of food items

39 Social and environmental factors involved in children's food rejections

40 Child's previous experiences and immediate environment Social facilitation effects

42 Summary

43 Conclusion and future directions

44 References

45

46 


\section{Introduction}

Food neophobia and picky/fussy eating behavior are presented as the two main forms of food rejections in children, and mostly concern the rejection of healthy items like fruits and vegetables (Brown, 2010; Cashdan, 1998; Carruth, Skinner, Houck, Moran, Coletta, \& Ott, 1998; Jacobi et al., 2003). Therefore they are responsible for the reduction of the child's dietary variety (Birch \& Fisher, 1998; Falciglia, Couch, Gribble, Pabst, \& Frank, 2000), along with a possible lack of essential micro-nutriments and fibers that are necessary for normal and healthy child development (Carruth et al., 1998).

A recent research review by Dovey, Staples, Gibson, and Halford (2008) provided an interesting and comprehensive understanding of the concepts of food neophobia and picky/fussy eating and how they affect children's dietary repertoire. However, despite extensive research in the area, the mechanisms underlying these two types of food rejection in children are still unclear, as the main factors influencing food rejection have not been clearly identified yet.Our aim is to review a range of research studies on food neophobia and picky/fussy eating so as to point to a series of factors that play a key role in food rejections in childhood. Accordingly, and unlike previous available research reviews, we emphasize the "cognitive factors" underlying food rejections in children. We use the notion of "cognitive factors" in the broad sense of the term, that is to say we include the following: food perception, mental representations and categorizations of food items, and emotions and feelings toward food. We also include a range of "social and environmental factors" as they might also significantly influence and modulate children's food rejections. To that end, a search of published research papers on children's food rejections was conducted using the ScienceDirect, PubMed, and JSTOR databases. We used a combination of keywords to compile peer-reviewed articles on the two constructs of interest (food neophobia and picky/fussy eating), and on the factors that influence these behaviors. Accordingly, "food neophobia", "picky-fussy eating”, “food aversion”, and "food rejection” were used jointly with "infants", "toddlers", and "children" as keywords, to circumscribe our research within the sensitive period of food neophobia (i.e., from 18 months to six years of age; see Cashdan, 1994). We additionally included studies on adults and nonhuman primates when they potentially revealed interesting aspects of food rejections.

We start with a brief summary of food neophobia and picky/fussy eating behavior regarding their definitions, measure assessments, developmental trends, and negative consequences on children's dietary repertoire. We then review a range of cognitive factors 
that potentially influence and explain food rejections in children. In the subsequent section we review social and environmental factors that may affect and modulate food rejections in children. We then summarize the findings to provide a comprehensive view of the factors involved in children's food rejections. We conclude by suggesting new lines of research.

\section{Food neophobia and picky/fussy eating behavior in children}

\section{Definitions}

Food neophobia is defined as the reluctance to eat, or the avoidance of, new foods (Dovey et al., 2008). This behavior is present among omnivorous species (Adessi, Galloway, Visalberghi \& Birch, 2005), and is considered an efficient adaptive strategy to avoid the risk of ingesting novel (unknown) and potentially poisonous items (see Milton, 1993; Rozin, $1977,1979)$. Whether or not food neophobia is a true phobia is an important question. The literature provides some good reasons to think it is. For instance, it has been shown food neophobia is associated with physiological responses reflecting fear toward novel foods (Raudenbush \& Capiola, 2012).Moreover, the fact that the same techniques have been used to treat food neophobia and other phobias (Marcontell, Laster, \& Johnson, 2003; Nicholls, Christie, Randall, \& Lask, 2001; Singer, Ambuel, Wade, \& Jaffe, 1992) also suggests that food neophobia actually belongs to the latter category.

Picky/fussy eating is defined as the rejection of a substantial number of foods that are familiar (as well as unfamiliar) to the children (Birch, Johnson, Andresen, Peters, 1991; Galloway, Fiorito, Lee, \& Birch, 2005; Smith, Roux, Naidoo, \& Venter, 2005; Story \& Brown, 1987). Picky/fussy eating may also include the consumption of an inadequate amount of food (Rydell, Dahl, \& Sundelin, 1995), or the rejection of certain food textures (Smith et al., 2005).

Another distinction between food neophobia and picky/fussy eating is based on the point of rejection of the food itself: unlike food neophobia, picky/fussy eating does not occur only before the tasting step, it may also occur after tasting is realized (Brown, 2010).

Since food neophobia is defined roughly as the rejection of novel or unknown food whereas picky/fussy eating is the rejection of a large proportion of familiar as well as unfamiliar foods, food neophobia is sometimes considered a subset of picky/fussy eating (Dovey et al., 2008; Potts \& Wardle, 1998; Raudenbush, van der Klaauw, \& Frank, 1995). In their review, Dovey et al. (2008) assumed that the two phenomena are behaviorally distinct (Pelchat \& Pliner, 1986; Pliner \& Hobden, 1992), because different factors predict the 
severity and expression of the two constructs (Galloway, Lee, \& Birch, 2003; Raudenbush et al., 1995; Potts \& Wardle, 1998). However, other authors argue that these two constructs are clearly related (Potts \& Wardle, 1998; Raudenbush et al., 1995; Wardle \& Cooke, 2008). There is no decisive empirical evidence in favor of a robust sharp distinction between food neophobia and picky/fussy eating. From a theoretical point of view, the definitions of these constructs are ambiguous in that they both depend on an unanalyzed (and viewpointdependent) notion of familiarity.

\section{Assessment of measures}

124 Food neophobia is usually measured by The Food Neophobia Scale (FNS) designed by Pliner and Hobden (1992).. Originally designed to score adults' neophobia, the FNS was then adapted to measure children's neophobia (Children Food Neophobia Scale, CFNS; Pliner, 1994). These measurement tools have successfully been used to predict Anglophone responders' attitudes toward new foods and have been translated into other languages, such as French (Ton Nu, MacLeaod, \& Barthelemy, 1996; Nicklaus, Boggio, Chabanet, \& Issanchou, 2005), Spanish (Fernandez-Ruiz, Claret, \& Chaya, 2013), and Italian (Laureati, Bergamaschi, \& Pagliarini, 2015). In addition, because food neophobia concerns mainly fruits and vegetables, Hollar and colleagues have recently adapted Pliner's work to investigate responders' attitudes toward these specific items (the Fruit and Vegetable Neophobia Instrument, FVNI; Hollar, Paxton-Aiken, \& Fleming, 2013).

In most studies using Pliner's scales (or adapted versions), parents were asked to complete the questionnaire to assess their child's food neophobia. This hetero-assessment raises several well-known difficulties which lead to the development of auto-assessment questionnaires, for instanceThe Food Situations Questionnaire (FSQ) designed for 7- to 12year-old Anglophone children Pliner (2000). Since this first attempt, two other questionnaires suitable for children have been developed, one in France (Reverdy, Chesnel, Sclich, Kôster, \& Lange, 2008; Rubio, Rigal, Boireau-Ducept, Mallet, \& Meyer, 2008), and the other in Italy (Laureati, Bergamaschi, \& Pagliarini, 2014). measurement. To date, this construct is usually assessed through general questionnaires on food habits, which include scales that measure problematic eating, fussiness, food neophobia, low enjoyment when eating, among others. Noticeable questionnaires are The Child Eating

147 Questionnaire (see Birch, Fischer, Grimm-Thomas, Markey, Sawyer, \& Johnson, 2001;

148 Tharner et al., 2014), The Child Eating Behavior Questionnaire (see Wardle, Guthrie, 
149 Sanderson, \& Rapoport, 2001), and The Children's Eating Difficulties Questionnaire (see

150 Rigal, Chabanet, Issanchou, \& Monnery-Patris, 2012). Other authors have recorded

151 picky/fussiness by simply asking parents whether or not their children are picky (Carruth,

152 Ziegler, Gordon, \& Barr, 2004; Jacobi, Agras, Bryson, \& Hammer, 2003; Jacobi, Schmitz, \&

153 Agras, 2008). These disparate methods may have added to the inconsistent understanding of

154 this construct. Clearly, there is a need for a more applicable, validated, and homogenous

155 picky/fussiness assessment method.

156

157

Developmental trends

158 Both food neophobia and picky/fussy eating are age-related and temporary behaviors, but

159 according to some authors each follows a specific developmental path (Dovey et al., 2008;

160 McFarlane \& Pliner, 1997).

161 On the one hand, neophobic behavior increases as a child becomes mobile, and peaks

162 between 2 and 6 years of age (Addessi et al., 2005; Cashdan, 1994; Cooke, Wardle, \&

163 Gibson, 2003; Harper \& Sanders, 1975). After that period, the expression of food neophobia

164 decreases (Koivisto-Hursti \& Sjöden, 1997), until it reaches a relatively stable plateau in

165 adulthood (McFarlane \& Pliner, 1997). According to some authors, there is a general decrease

166 until early adulthood (Koivisto-Hursti \& Sjöden, 1996; Raynor \& Epstein, 2001; Rigal,

167 Frelut, Monneuse, \& Hladik, 2006). From an evolutionary point of view, one plausible

168 hypothesis is that food neophobia attenuates because dietary variety is essential to the survival

169 of omnivorous species. But some studies suggest that the neophobic behavior remains stable

170 from adolescence (13 years old) until adulthood (Nicklaus et al., 2005). Note that the decline

171 in food neophobia implies overcoming the fear induced by the presentation of a novel food

172 item. Therefore, the mere fact that fewer things are novel for an adult or an adolescent than

173 for a child, automatically reduces the gradient at which food neophobia disappears (Cooke \&

174 Wardle, 2005).

175

On the other hand, picky/fussy eating increases during infancy. Overall, 19\% of 4- to 6 month-old infants were judged to be picky by their mothers whereas this percentage rises to $50 \%$ in the 19- to 24-month-old children (Carruth et al., 2004). The prevalence of this behavior was shown to remain relatively stable during early childhood from 2.5 to 4.5 years of age (Dubois, Farmer, Girard, Peterson, \& Tatone-Tokuda, 2007). The precise

181 developmental path of picky/fussy eating is however unknown and a variety of factors may

182 bias the understanding of it(Dovey et al., 2008; Wardle, Herrera, Cooke, \& Gibson, 2003). A 
recent longitudinal study by Mascola, Bryson and Agras (2010) showed that the highest incidence of picky/fussy eating occurs in early childhood (at around 2 years), and declines to very low levels by the age of 6 years.

\section{Cognitive factors involved in children's food rejections}

In this section we review research studies on the potential cognitive mechanisms that underlie food rejections during the sensitive period of food neophobia and picky/fussy eating. We use "cognition" in the broad sense of the term, that is to say we included any kind of operations on mental representations, understood as theoretical or concrete entities whose role is to convey information coming from the world. Within this framework, we incorporated the following: i) how information (food) is perceived; ii) how information is internally represented and categorized; and iii) how emotions and feelings accompany and affect food processing. Indeed, as stressed by Marcel Proust, cognition is often colored by various feelings and emotions in the food domain (Damasio, 2005).

\section{Food perception mechanisms}

A variety of perceptual cues contribute to the visual evaluation of food (Wadhera \& CapaldiPhillips, 2014). These cues have a key role in food rejection mechanisms, as food rejections in toddlers primarily occur on sight.

It has been shown that vision is more important than touch in the process of sensory decision making in children, unlike adults who use touch more than vision (Dovey, Aldridge, Dignan, Staples, Gibson, \& Halford, 2012). Indeed, children generally use color rather than shape to classify novel food items whereas they use shape rather than color to classify novel items if they think the novel items are something to play with (Macario, 1991). It is plausible that food behavior depends partly on preferences for certain colors in the food domain. For instance, green vegetables are more often rejected (Harris, 1993), and their acceptance is difficult to foster (Mennella, Nicklaus, Jagolino, \& Yourshaw, 2008) compared to orange vegetables (Gerrish \& Mennella, 2001). Some research suggests that toddlers have a hypothesis about the predictive validity of color in the food domain (Macario, 1991).

The visual presentation of the novel food is obviously important. The consumption of a novel fruit can be promoted through a visually appealing presentation (Jansen, Mulkens, \& Jansen, 2010). Children from 5 to 12 years of age also have a clear preference for a variety of 
food items, a variety of colors, and space between items on their plates more than adults do(Zampollo, Kniffin, Wansink, \& Shimizu, 2012), and for having their vegetables cut into geometric shapes at 9-12 years (Olsen, Ritz, Kramer, \& Møller, 2012). Moreover,some aspects of the mode of presentation of the food affect children's food behavior, maybe by helping the child to identify the food items. This hypothesis is consistent with the fact that picky/fussy children are less likely to consume dishes that were mixed together and thus harder to identify (Carruth et al., 2004), and with parents' reports according to which children like "food where all of the ingredients are without sauce and easily identifiable" (Cashdan, 1998, p.623).

Beyond color, it has been shown that children are sensitive to local changes such as food containing "bits" or pips (Wardle \& Cooke, 2008. For instance, Werthmann and colleagues (2015) manipulated the color, the texture and the taste of yoghurts offered to the children. In that context, they observed that lumpy texture influenced yoghurt acceptance understood as the number of spoons the children consumed. More generally, one sensory cue that can elicit food rejection, through disgust before tasting, is visually perceived texture (Martins \& Pliner, 2006). For instance, evidence suggests that a texture fading strategy, a gradual addition of higher textures based on the result of periodic probes, can be effective to treat food selectivity in toddlers (Johnson \& Babbitt, 1993; Shore, Babbitt, Williams, Coe, \& Snyder, 1998).

Regarding olfaction, some research studies mention that neophobic young adults rated the odors of foods as less pleasant and sniffed them less vigorously (Raudenbush, Schroth, Reilley, \& Frank, 1998). They also have weaker odor identification abilities (Demattè et al., 2013) than neophilic young adults. However, to our knowledge, in young children only a difference in sniffing proximity has been found (Bunce \& Gibson, 2012).

However,the large majority of sensory preferences above-mentioned are not innate (Desor, Maller, \& Turner, 1973; Harris, Thomas, \& Booth, 1990; Rosenstein \& Oster, 1988). Rather, most of our food choices are learned through exposure (Birch, Gunder, GrimmThomas, \& Laing, 1998; Birch \& Marlin, 1982; Birch, Mcphee, Shoba, Pirok, \& Steinberg, 1987; Nicklaus et al., 2005; Pliner, 1982; Wardle et al., 2003).The following paragraphs are devoted to review the different forms of exposure influencing food preferences and acceptance.

It has been shown that visual exposure during infancy increases the appeal of a target food and of food items similar to the target (Birch et al., 1998), thereby reducing food neophobia (Birch et al., 1987). Similarly, the early introduction of a variety of solid foods was shown to 
251 foster the child's acceptance of solid foods (Gerrish \& Mennella, 2001; Mennella et al., 252 2008). Interestingly, the effect was strengthened when a variety of foods was presented both within meals and between meals (Mennella et al., 2008). successful acceptance of a target food into the child's dietary repertoire (Birch et al., 1987; Wardle, Carnell, \& Cooke, 2005; Wardle et al., 2003). Interestingly, the number of exposures to reach food acceptance is also age-dependent. During the first year of life a single positive exposure can lead to the acceptance of the novel item (Birch et al., 1998). This interaction with novel food items may result in a different habitual diet (Skinner \& Carruth, 2002). However, exposure effects are limited. For instance, while visual exposure produces enhanced visual preference judgments, it does not produce enhanced taste preferences (Birch et al., 1987). Thus, exposure to food in one particular modality will produce a change in preference within that modality only (Birch et al., 1987). Moreover, the effect of early exposure to foods does not generalize since repeated exposure to fruits does notvegetables at least in very young children from 4 to 7 months of age (Birch et al.,1998). Even in the same category (i.e., vegetables), repeated exposure to one item (pureed potatoes) does not promote acceptance of other items belonging to the same category (carrots) (Mennella et al., 2008).

Despite evidence that repeated exposure may increase acceptance of a target food, two potential problems may occur. The first one is "sensory specific satiation", or the reduction of a food's hedonic value after consumption (Rolls, 1986; Temple, Chappel, Shalik, Volcy, \& 271 Epstein, 2008). The effect can lead to food rejection in infancy (Mennella \& Beauchamp, 272 1999) and early childhood (Birch \& Deysher, 1986). Interestingly, consumption is not even necessarily required to produce a reduction in reported liking. Indeed, the sensory specific satiety can be olfactory (Rolls \& Rolls, 1997). The second problem is "monotony" (Rozin \& 275 Vollmecke, 1986), through which a prolonged access to a small number of unchanging foods 276 produces lower rating of liking. For instance, it has been shown that while exposure decreases 277 children's willingness to taste familiar ${ }^{1}$ vegetables, it increased their willingness to taste 278 unfamiliar fruits (Houston-Price, Butler, \& Shiba, 2009). Research studies have also 279 highlighted a decline in pleasantness of the appearance of eaten foods relative to uneaten 280 foods, a phenomenon called appearance-specific satiety (Wadhera \& Capaldi-Phillips, 2014).

\footnotetext{
${ }^{1}$ In that study, familiarity with a food stimulus is determined on the basis of the frequency of encounter with the food item reported by the parents. "Unfamiliar" means encountered less that once per month according to the parents answers to the Food Familiarity Questionnaire.
} 
In spite of these qualifications, the positive effect of repeated exposure on preferences and attitudes toward food is a now matter of consensus. However, the exact nature of the mechanisms underlying exposure remains unclear. The standard view is that the missing link between exposure and positive effects on preferences is a certain feeling of recognition/familiarity (Tichener, 1910 quoted in Zajonc \& Markus, 1982). Recognition (as well as categorization) decisions "(...) involve similarity computations performed on a common representational substrate, namely collection of individual exemplars." (Nosofsky, 1992, p. 392). Our hypothesis in line with Tichener's thought is that exposure enriches that "collection" which in turn has positive effects on food preferences and behavior.

\section{Mental representations and categorization of food items}

If exposure does affect positively food preferences and behavior in young children (and thereby is a psychological lever to overcome food rejections) because it facilitates a particular type of recognition process, it is likely that food rejections could, on the contrary, be associated with a certain type of recognition deficiency. To assess this hypothesis, we review the recent results on the development of categorization abilities in young children. On the basis of these results, we argue that the developmental characteristics of the categorization system might contribute to an explanation of food rejections. Research on food categorization and mental representations in humans has shown that before 2 years of age, infants show very limited ability to differentiate food and non-food items based on their relevant visual properties. For instance, 9-month-old infants were shown to equally direct their attention to domain-relevant properties, such as color and texture, and domain-irrelevant properties (such as the shape of the food's container) (Shutts, Condry, Santos, \& Spelke, 2009). Between 16 and 29 months of age, more than half of the children were willing to put crayons, dish soaps, and even imitation feces in their mouth (Rozin, Hammer, Oster, Horowitz, \& Marmora, 1986). Also, children under 2 years were more likely to accidentally poison themselves than older peers (Cashdan, 1994). This surprisingly indiscriminate behavior in infants might be attributed to the fact that human infants rely on adults to guide their eating until 2 years of age (Cashdan, 1994, 1998). Accordingly, infants may learn about food through observing others' behavior, actions, and emotions, rather than by evaluating and classifying foods solely on the basis of relevant perceptual properties.

However, a rapid change occurs between 2 and 3 years of age, when children begin to

313 categorize and reason about food items. At around 3 years of age, children were shown to

314 generalize learned knowledge about novel foods according to color, texture, and odor 
315 information, whereas they generalized learned knowledge (including linguistic knowledge ${ }^{2}$ )

316 about novel artifacts according to shape (Lavin \& Hall, 2001; Macario, 1991; Santos, Hauser,

$317 \&$ Spelke, 2002). Namely, 3- and 4-year-old children were more disposed to use color than

318 shape to classify novel items when they think the items are something to eat.

319 A research study by Nguyen and Murphy (2003) showed that 3-year-old children have

320 taxonomic and script categories for food. Taxonomic categories are organized into hierarchies

321 of increasingly abstract categories, such as terrier-dog-mammal-animal, and are based on

322 common properties or similarity. Script categories are formed when items play the same role

323 in a schema for a routine event (e.g., eggs and cereal are both in the script category of

324 breakfast foods). From age 4, children are able to cross-classify items, meaning they can

325 subsume a food item under both taxonomic and script categories (Nguyen \& Murphy, 2003).

326 It has been claimed that the rapidity with which children (3-year-olds) as well as

327 baboons and chimpanzees are able to categorize, in particular in the food domain, is "likely to

328 result from the early construction of a food category, because of its importance in their daily

329 life" (Bovet, Vauclair, \& Blaye, 2005, p. 57). Food neophobia peaks around 2-3 years of age,

330 that is to say precisely the period during which a food categorization system starts developing

331 in the child's cognition. From this perspective, Dovey et al. (2008) suggested that "children

332 build up schemata of how an acceptable food should look, and perhaps smell, and so foods

333 not sufficiently close to this stimulus set will be rejected” (p. 183). Similarly, Brown (2010)

334 suggested that some foods are rejected on sight because they do not match a prototypical

335 representation $^{3}$ or category of food in children's cognition.

\section{Emotions and feelings about food}

338 Emotions and feelings about food are intimately associated with food rejections (MacNicol,

339 Murray, \& Austin, 2003). Among negative emotions, disgust has been related to food

\footnotetext{
${ }^{2}$ In an experiment conducted by Lavin \& Hall (2001), 3 years old children were taught a neutral word " $X$ " referring to an unfamiliar object. The object was either described as being a toy or a food. Then the experimenters ask the subjects to extend the word " $X$ " to one of two other objects. One object differed in shape with the initial object, the other object differed in color, texture or smell. The results reveal that children were more likely to select the same-shaped entity only when the initial object was described as being a toy.

${ }^{3}$ The three competing views about categories are the exemplar, the prototype, the knowledge theories (see Murphy, 2002). At the end of the previous section on the perceptive mechanisms, we quoted Nosofsky (1992) who seems to endorse the exemplar theory. By contrast, we now mention Dovey (2008) and Brown (2010) respectively using the notions of schemata and prototypes which have a prototype theory flavour. We will not cut the Gordian knot in the present review because it seems that we are still in need of a precise and reliable method to "gain a window on the exact nature of children's conceptual representations." (Murphy, Ibidem, p. 383). Moreover, we share Murphy's opinion that for "real-life concepts, we would do best not to assume that a single form of conceptual representation will account for everything" (Ibid., p.65)
} 
neophobia (Tuorila et al., 2001), specifically in children after age 4 (Fallon, Rozin, \& Pliner, 1984; Rozin, Millman, \& Nemeroff, 1986) and in adults (Nordin, Broman, Garvill, \& Nyroos, 2004). For some authors, the feeling of disgust, and the corresponding facial expressions, may be associated with food items that are bitter and/or potentially harmful for the subject (Martins \& Pliner, 2005; Stein 1973). Food rejections based on disgust are sometimes assumed to imply high-level/conceptual representations regarding the nature and the origin of the rejected substance (Fallon et al., 1984). Accordingly, genuine disgust-based rejections might not occur below the age of 4 or even 7 , because they require that children have mastered an adult-like concept of contagion (Fallon et al., 1984).

However, some studies highlighted that some aspects of contamination and contagion can influence even young children, who showed some understanding of the transfer of properties instantiated by one item to another (Cashdan, 1998; Rosen \& Rozin, 1993; Siegal, 1988; Springer \& Belk, 1994; Toyama, 1999). Because some aversive properties of food items can be visually perceived, like aversive textural properties (Martins \& Pliner, 2006), disgust-based rejections may also occur on the basis of visual experience without appealing to complex conceptual representations of contamination (Brown \& Harris, 2012a).

Food neophobia is connected to an increase in anxiety over food (Galloway et al., 2003; Pliner, Eng, \& Krishnan, 1995; Pliner \& Hobden, 1992; Pliner, Pelchat, \& Grabski, 1993). Moreover, even an increase in anxiety that is not initially related to food might increases the neophobic response (Pliner et al., 1995). Interestingly, it has been shown that when a child is pressured to consume a food item while he/she is experiencing disgust toward it, the disgust and the correlated anxiety response are likely to increase. This may result in a long-lasting food aversion (Batsell \& Brown, 1998; Batsell, Brown, Ansfield, \& Paschall, 2002). By contrast, foods highlighted positively, pairing the foods with positive emotional expressions, emotional words or safety information, are more likely to be accepted (Martins, Pelchat, \& Pliner, 1997; Pelchat \& Pliner, 1995). The direction of the observed relationship between disgust/anxiety and food aversion is unclear. Some authors have suggested that disgust could trigger food rejection (Brown \& Harris, 2012b; Toyama, 2000). Alternatively, it has recently been argued that disgust could be a catalyst for food neophobia (Brown \& Harris, 2012a).

A causal link is suspected between strong forms of picky/fussy eating and a personality trait called "tactile defensiveness" (Nederkoorn, Jansen, \& Havermans, 2015). Tactile defensiveness is defined in many different ways in the scientific literature (see 
seminal work of Ayres, 1963; see also Smith et al., 2005; Wilbarger, 2000). The notion includes overreactions to the experiences of touch, or rejections or withdrawal responses to some typically inoffensive tactile stimuli perceived as offensive. This disposition could impact the expectation of enjoyment of certain perceived textures and consequently the child's eating behavior. More precisely, it has been shown that tactile defensive children refused vegetables to a higher degree than non-tactile defensive ones (Smith et al., 2005).

Another personality trait whose influence on food neophobia is discussed in the literature is the "sensation seeking disposition" (measured via the sensation seeking scale) (Zuckerman, 1979). Persons who are high sensation seekers, that is to say people who require a lot of stimulation to reach the appropriate level of arousal, are more open to new food experiences, and thus tend to be less neophobic (Galloway et al., 2003; Pliner \& Melo, 1997). In this case, low food neophobia would be a particular mode of a lower general neophobia (Pliner \& Hobden, 1992).

Finally, some studies (Blisset \& Fogel, 2013, Keller, Steinmann, Nurse, \& Tepper, 2002) have associated another trait called "bitterness sensitivity" to food dislike and rejections. Bitterness is known to serve as a warning about poisonous foods, especially vegetables (Bradbury, 2004; Catanzaro, Chesbro, \& Velkey, 2013) and has been reported as a sensory deterrent for vegetable consumption (Dinehart, Hayes, Bartoshuk, Lanier, \& Duffy, 2006). The ability to detect bitterness in a certain food item is a genetic trait encoded through specific genes, such as TASR38 encoding for the phenylthiocarbamide (PTC) taste receptor (Bufe et al., 2005; Kim, Jorgenson, Coon, Leppert, Risch, \& Drayna, 2003). It has been shown that individuals with low thresholds for PTC (thus highly sensitive to bitterness) display more food dislikes and rejections than those with high thresholds (thus less sensitive to bitterness; Blisset \& Fogel, 2013; Dinehart et al., 2006; Keller et al., 2002). Moreover highly sensitive individuals seem to be more picky eaters and less adventurous (Catanzaro et $a l ., 2013)$. However, according to some other studies "bitterness sensitivity" does not predict food preferences and rejections (Jerzsa-Latta, Krondl, \& Coleman, 1990; Mattes \& Labov, 1989).

\section{Social and environmental factors involved in children's food rejections}

In this section we review research studies on the potential social and environmental factors underlying food rejections during the sensitive period of food neophobia and picky/fussy eating. These factors are important because the very act of eating is a socially grounded 
behavior (see e.g., Shutts, Kinzler, \& DeJesus, 2013). Food consumption is socially and

409 culturally shared with congeners, and is based on previous experiences and previously acquired habits in the food domain. We first address the role played by the child's previous experiences (antecedents) and immediate environment (namely, parental practices). We then focus on the role played by the social context on food behavior, focusing on social facilitation

\section{3 effects.}

\section{Child's previous experiences and immediate environment}

A handful of studies suggested that the antecedents of the child play an important role in the determination of the child's food preferences and rejections. These antecedents are the child's genes and prenatal food experiences.To estimate the genetic influence, Cooke, Haworth, and Wardle (2007) compared intraclass correlations between monozygotic pairs of twins and dizygotic pairs of twins for food neophobic phenotypes. They concluded that food neophobia is highly heritable and is partly in the genes. Regarding prenatal experiences, evidence suggests that babies develop preferences for flavors they have experienced through amniotic fluid and breast milk ( Schaal, Marlier \& Soussignan1998, Mennella, Jagnow, \& Beauchamp, 2001).

Taste preferences can also be learnt by means of conditioning. If a child is exposed to repeated pairings of a particular taste (neutral stimulus) with a positive satiety effect, this taste will come to elicit that pleasurable state which in turn will lead to preference for that taste. This form of classical conditioning mainly concern the taste of foods which are energy dense (sweet or rich in fat, carbohydrate) (Birch, McPhee, Steinberg, \& Sullivan,1990 ; Johnson, McPhee, \&Birch, 1991; Kern, McPhee, Fisher, Johnson, \& Birch, 1993). However, Havermans and Jansen (2006) observed in 13 young children (M age: 5.2 years) a significant increase in flavor preference for the vegetable taste paired with dextrose. Even if the long term effects remain unclear, it has been recently shown that caloric conditioning can be combined fruitfully combined with another powerful mechanism: social learning/modelling (Jansen \& Tenney, 2001) which is discussed in the next section. Regarding the influence of the child's (post-birth) immediate environment on his/her food behavior, certain characteristics of the primary caregiver significantly affect food neophobia expression in children (Dovey et al., 2008). The most obvious is parental food neophobia (Carruth \& 
439 Skinner, 2000; Pelchat \& Pliner, 1986, 1995; Pliner, 1994) ${ }^{4}$, but socio-economic status

440 (Flight, Leppard, \& Cox, 2003; Giskes, Turrell, Patterson, \& Newman, 2002; Lien, Jacobs, \&

441 Klepp, 2002) and educational level (Vereecken, Keukelier, \& Maes, 2004) also seem to

442 modulate the degree of expression of the disposition to reject fruits and vegetables.

443 Parental practices are clearly important in determining the child's acceptance of versus

444 aversion toward food items because they impact both flavor exposure through milk (maternal

445 compared to formula) and social aspects guiding food behavior. The difficulty is of course to

446 disentangle the respective contributions of these two types of factors.During infancy, different

447 parenting and nutrition-related attitudes in mothers could positively influence the subsequent

448 food behavior of the child (Taveras, Scanlon, Birch, Rifas-Shiman, Rich-Edwards, \&

449 Gillman, 2004). For instance, infants were shown to eat more formula when caregivers

450 provided social interaction during feeding (Lumeng, Arbor, \& Blass, 2007). Compared to

451 formula-feeding, breastfeeding may facilitate the future acceptance of solid foods (Sullivan \&

452 Birch, 1994; Nicklaus, 2009). Girls were shown more likely to be picky/fussy if they were

453 breastfed for fewer than 6 month(Galloway et al., 2003). Moreover, some research studies

454 have observed statistical relationships the between mother's diet, the nature of their parental

455 strategies, and the behavioral dispositions of their daughters toward fruits and vegetables. In a

456 nutshell, mothers's with a dietof more fruits and vegetables seemed to be less disposed to

457 pressure their daughters to eat and had daughters who were less picky/fussy and who

458 consumed more fruits and vegetables during childhood (Galloway et al., 2005).

459 Evidence suggested that high controlling parental practices, including restriction and

460 pressure to eat, created an emotionally negative environment around food, with negative

461 consequences for children's reactions to food (Birch et al., 1987; Faith \& Kerns, 2005;

462 Galloway, Fiorito, Francis, \& Birch, 2006; van der Horst, 2012; Webber, Cooke, Hill, \&

463 Wardle, 2010). Some studies indeed revealed that many long-lasting food dislikes and

464 rejections could be traced back to forced consumption episodes involving an authority figure

465 (parent or teacher) (Batsell et al., 2002). It has also been shown that parental attempts to

466 control food intake in children reduces the positive effect of exposure (Galloway et al., 2006).

467 Some data showed that presenting a food as a reward enhanced children preference for that

468 food (Birch, Zimmerman, \& Hind, 1980). By contrast, when disliked foods are used as a

\footnotetext{
${ }^{4}$ However, further research is needed to determine either the direction of a putative causal arrow between the variables or rather the existence of a vicious circle.
} 
469

470

471

472

473

474

475

476

477

478

479

480

481

482

483

484

485

486

487

488

489

490

491

492

493

494

495

496

497

498

499

500

501

reward, these foods become even less desirable (Birch \& Marlin, 1982; Birch, Marlin, \& Rotter, 1984).

It is hard to determine what parents think about these coercive strategies. On the one hand, some evidence suggested that most parents know that these strategies are ineffective (Casey \& Rozin, 1989). On the other hand, research studies showed that when infants are between 6 and 12 months old, mothers use pressure and restriction in reaction to the perceived size of their child (Brown \& Lee, 2011). It is worth noting that the direction of the causal arrow between parental pressure and children's reactions to food is unclear (Galloway et al., 2005, 2006). Namely, we do not know whether children's food rejections elicit more parental pressure, or whether parental pressure and restriction foster food rejections in children. Avicious circle including both aspects is a living option.

Interestingly, research studies suggested that children's participation in and enjoyment of cooking has a direct influence on picky/fussy behavior but also increases eating enjoyment, which in turn decreases picky/fussy eating (van der Horst, 2012). This is explained by the fact that through cooking, children are exposed to a wide variety of foods. A cooking context is also positive, as most children like hands-on activities and the concrete results of these activities can give them a feeling of ownership and pride (van der Horst, 2012). Modifying the home food environment through activities that engage both parents and children can be a key factor in the improvement of food intake in children and can increase consumption of fruits and vegetables (Heim, Bauer, Stang, \& Ireland, 2011).

\section{Social facilitation effects}

Shutts et al. (2013) stated that "humans at any age rarely face the challenge of food selection alone. (...) Infants and young children therefore have numerous opportunities to watch members of their culture choose, cook, eat, and react to different kinds of foods in social settings" (p. 420). Accordingly, one major influence of the social context on children's reaction to food is social modeling or social facilitation. Clayton (1978) defined "social facilitation" as an increase in the probability of performing a class of behaviors in the presence of conspecifics performing the same class of behaviors at the same time (see also Tomasello \& Call, 1997; Visalberghi \& Fragaszy, 1990; Whiten \& Ham, 1992). Put differently, social facilitation means that when a child eats in the presence of others eating food, his/her behavior is socially facilitated toward food intake (see Herman, 2014, for a recent review of the social facilitation of eating). 
Research studies in this area have shown that social facilitation effects are not restricted to humans. They are observed in many omnivorous species, such as chacma baboons (Cambefort, 1981), tufted capuchin monkeys (Visalberghi \& Fragaszy, 1995; Visalberghi \& Addessi, 2000), rhesus macaques (Weiskrantz \& Cowey, 1963), juvenile and infant marmosets (Vitale \& Queyras, 1997; Voelkl, Schrauf, \& Huber, 2006), gerbils (Forkman, 1991), rats (Galef, 1993), and human children (Harper \& Sanders, 1975). Interestingly, monkeys were shown to exhibit a social facilitation effect even across species (i.e. from an human model) (Santos et al., 2002).

In human children, unlike other primates, social facilitation effects are specific. Adessi et al. (2005) have shown that young children aged 2-5 years learned to accept new foods through observing significant others eating the same food (but not if the food is different or if the model is present without eating). By contrast, capuchin monkeys accepted and ate more of a novel food when their group members were eating a food, even if it had a different color (Addessi \& Visalberghi, 2001; Visalberghi \& Fragaszy, 2002; Visalberghi \& Addessi, 2000). Adults can serve as models for food acceptance: an encouraging teacher (Hendy \& Raudenbush, 2000; Highberger \& Carothers, 1977) or a friendly visitor in a classroom can foster food acceptance in young children (Harper \& Sanders, 1975). However, one person has a limited effect and the greatest effect occurs when everyone in the immediate environment of the child is eating the food (Birch, 1980). In addition, the social facilitation is enhanced when models are familiar to the children (Salvy, Vartanian, Coelho, Jarrin, \& Pliner, 2008). Harper and Sanders (1975) showed that children aged 14-20 and 42-48 months were willing to put unfamiliar foods in their mouth when adult models were eating the food, more than when adult models were simply offering the food; but the facilitation was more effective when the mother was the source of the food than when the food came from a stranger.

In the same vein, Shutts, Kinzley, McKee, and Spelke (2009) showed that 12-monthold children selected a food endorsed by an adult speaker of the child's own language over one endorsed by an adult speaker of a foreign language, even when the children knew that both foods were highly palatable. Salvy et al. (2008) showed that social facilitation occurred in children aged 5-11 years only when the co-eaters were familiar: children eating alone or with strangers ate less than children eating with their siblings. Social facilitation with peer modeling appeared to be the most effective way to foster novel food acceptance, as shown in children aged 2-4 years (Birch, 1980) and children aged 3 and 6 years (Hendy, 2002). Interestingly, the effects of peer modeling are long lasting as they endure beyond the immediate context in which the modeling occurred (Birch, 1980; Laureati et al., 2014). Two 
recent studies also showed that social modeling of food intake by children was enhanced when the peers acting as models (on TV) displayed emotions instead of a neutral expression (Bevelander et al., 2013), and when other approaches were combined with peer modeling (such as food exposure and rewards; Laureati et al., 2014).

Interestingly, many research studies revealed that social facilitation could also change the food preferences of children (Laureati et al., 2014). More precisely, if preschool children were exposed to peer models who were choosing and eating a target food that did not belong to the set of foods initially preferred by the children, the probability that the children chose the target food increased. The effect of peer modeling was such that a significant number of children ended up choosing the target food even when presented with an initially preferred food (Birch, 1980; Hendy, 2002). These results confirm the Social Cognitive Theory (Bandura, 1997), according to which peer models are one of the social factors that most effectively foster food acceptance during preschool lunch.

Finally, it is worth mentioning that there is conflicting evidence in the literature as to whether younger children are more affected by the behavior of peers than older ones. For instance, Birch (1980) has found that food preferences of 3-year-old children are more socially affected than those of 4-year-old children. Lumeng's investigations of social cognition development in infancy (Lumeng, 2013) supported this perspective and showed that between 3 and 4 years old, children develop the capacity to modify their food choices, based on the understanding that adults can have different food preferences than their own and can provide false information about food items. Younger toddlers who are not capable of this mind reading would therefore be more affected by the behavior of parents pretending to like usually rejected food items. But another study has not found such a difference between two groups of children, aged 14-20 months and 42-48 months (Harper \& Sanders, 1975). A similar conflicting evidence exists regarding the impact that sex/gender has on peer models' ability to modify children's food preferences. According to some authors, girls are more influenced than boys (Hendy \& Raudenbush, 2000), but older research studies have not found such sex/gender differences (Birch, 1980).

\section{Summary}

To summarize, food neophobia and picky/fussy eating behavior in children have been shown to contribute to food rejections (mostly concerning healthy items such as fruits and vegetables) and reduction of dietary diversity. Hence these two phenomena have negative 
consequences for health, and a better understanding of the factors underlying food rejections

571 will help to overcome these concerns.

The following diagram proposes a review of the different factors (displayed in boxes) presented above (see Fig. 1). The structure of this diagram is similar to the structure of the 574 present review.

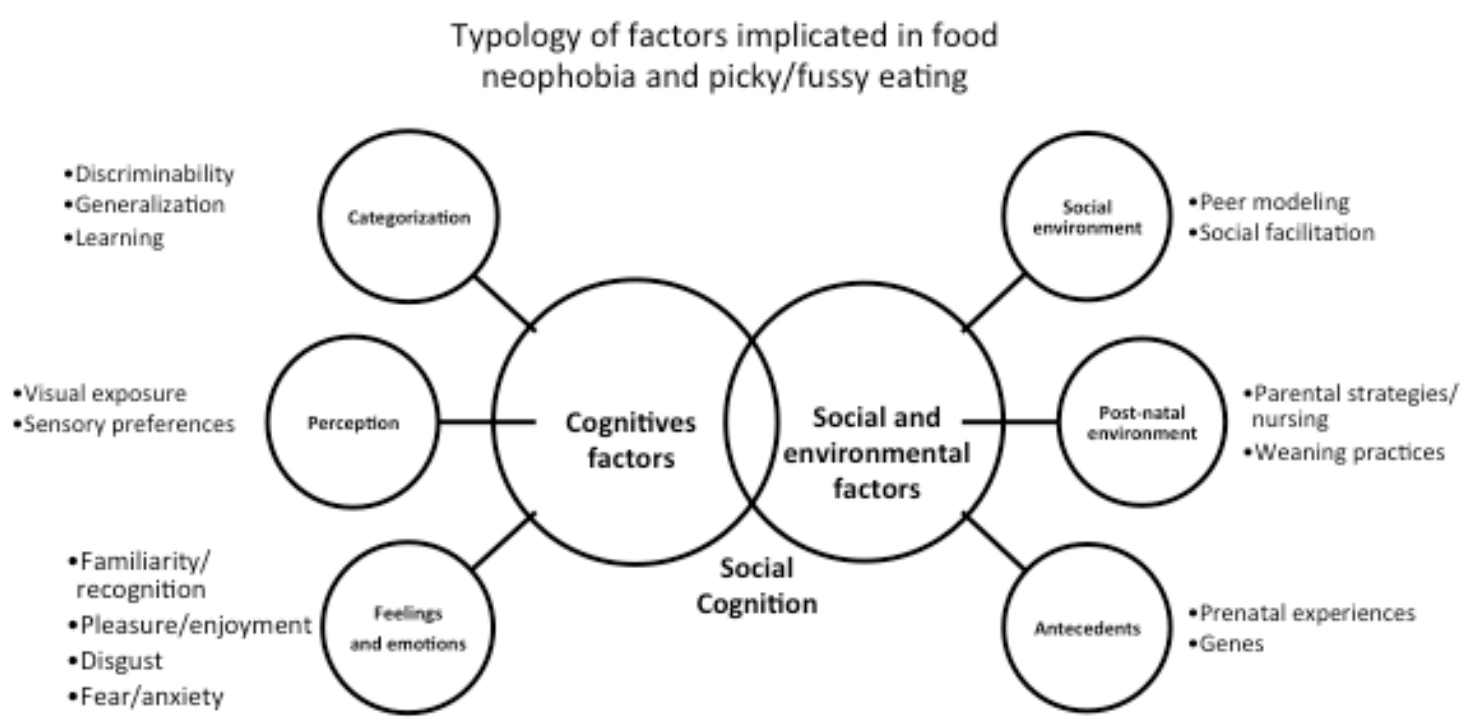

Fig1.

Visual and olfactory cues play a key role in food rejections. It is likely that food neophobia and pickiness depend partly on preference for certain perceptual properties of food (color, visually perceived texture, shape, smell, etc.) or even mode of presentation. For instance, it is possible that some children prefer dishes with space between items because overlaps can cause contamination-based disgust. In addition, because the large majority of preferences are learned through experience, food rejections are often reduced by repeated visual exposure during infancy.

Information given by the physical context is perceived and categorized by the child, with the food categorization system possibly delivering output on edibility, familiarity, or attractiveness of items. Because food rejections peak around 2-3 years when rapid improvements appear in the categorization system, one might consider food neophobia and pickiness the result of a perceptual mismatch between food items and prototypical food categories embedding perceptual properties. Besides, some traits, such as bitterness 
sensitivity, sensation seeking disposition, or tactile defensiveness, may influence children's perception of and feelings toward foods and thus lead to potential rejections.

The capacity to select non-dangerous foods in early childhood mainly depends on learning from others. Thereby, facilitation and modeling effects play major roles in children's willingness to try new food and even in changing their food preferences. Food selection is a risky endeavor and even if children understand that models can provide false information they assume that the latter will at least target safe foods. Children's inclination to modify their choices based on mind reading seems to be weaker for food than non-food items and therefore the food domain is a specific and unique domain in social cognition. Food neophobia and pickiness are also influenced by genetics and prenatal food experiences (namely flavors experienced through the amniotic fluid), as well as breastfeeding and weaning practices. The child's immediate environment after birth (cultural customs, socio-economic status, characteristics of the caregiver) should also be taken into account because it might influence how foods are presented and accepted.

\section{Conclusion and future directions}

608 Food rejections by children have been referred to as food neophobia and pickiness behaviors, 609 but the conceptual definitions and assessments of these two constructs as well as their interrelations are still not entirely clear. In addition, the literature showed that food rejections by children fell under the scope of multiple cognitive and social/environmental factors. Whereas the role played by some of these factors (namely the social and environmental factors) has been extensively investigated, the implications of other factors, such as children's developing food categorization system, have been comparatively under-researched. In our view, there is a need for studies on food rejections, regarding (i) the distinction between food neophobia and picky/fussy eating, and (ii) the potential link between food categorization abilities and children's food neophobia and pickiness.

First, the literature lacks decisive empirical evidence in favor of an independence or a correlation between the two components of food rejection, food neophobia and pickiness. To clarify this aspect, it would be useful, for instance, to conduct psychometric studies in order to develop and validate a scale of food rejections for children, including items relative to food neophobia and pickiness behaviors. Specifically, investigations of the factorial structure of such a scale would help to disambiguate the relationships that food neophobia and picky/fussy eating entertain with one another. The scientific study of children's food rejections, including 
625 the efficacy of techniques for reducing them, would also be greatly facilitated by such a 626 measurement tool.

627 Second, from a developmental perspective, few studies have yet linked cognitive 628 capabilities of children and their inclination toward food rejections. Food rejections peak at 629 around 2-3 years, precisely when rapid changes and improvements appear in the child's food 630 categorization system. In our view, the concomitance of these two phenomena is not a sheer 631 coincidence, and calls for investigation. An important role of the food categorization system 632 is to deliver edibility output, that is to say, to discriminate food items from non-food items.

633 However, little is known about the properties of this function's development, or about its

634 relation to children's food neophobia. Future studies might assess the developmental

635 characteristics of children's food categorization system during neophobia's peak, and test i)

636 whether children's level of food rejection is a behavioral manifestation of the developmental

637 characteristics of their food categorization system and ii) whether children's level of food

638 rejection acts as a variable that moderates (as silencer or an enhancer) their developing ability

639 to discriminate between food and non-food items. We are currently designing studies with this 640 objective.

641

642 Acknowledgements

643 The authors would like to acknowledge the financial support from the Fonds Français pour 644 l'Alimentation et la Santé. This review has been written during the first author's postdoc at 645 PsyCLÉ and IPBR, he would like to thank these institutions. We would like to thank Dr. 646 Camille Schwartz who initiated this project, and Kathryn Rhett Nichols who proofread our 647 article. 


\section{References}

653

654

655

656

657

658

659

660

661

662

663

664

665

666

667

668

669

670

671

672

673

674

675

676

677

678

679

680

681

Addessi, E., Galloway, A. T., Visalberghi, E., \& Birch, L. L. (2005). Specific social influences on the acceptance of novel foods in 2-5-year-old children. Appetite, 45(3), 264271.

Addessi, E., \& Visalberghi, E. (2001). Social facilitation of eating novel food in tufted capuchin monkeys (Cebus apella): input provided by group members and responses affected in the observer. Animal Cognition, 4(3-4), 297-303.

Ahern, S. M., Caton, S. J., Bouhlal, S., Hausner, H., Olsen, A., Nicklaus, S., \& Hetherington, M. M. (2013). Eating a rainbow. Introducing vegetables in the first years of life in 3 European countries. Appetite, 71, 48-56.

Ayres, A. J. (1963). The development of perceptual-motor abilities: a theoretical basis for treatment of dysfunction. The American Journal of Occupational Therapy, 17, 221-225.

Bandura, A. (1997). Self-efficacy: The Exercise of Control. New York: Freeman \& Company.

Batsell, W. R. J., \& Brown, A. S. (1998). Human flavor-aversion learning: a comparison of traditional aversions and cognitive aversions. Learning and Motivation, 29(4), 383-396.

Batsell, W. R. J., Brown, A. S., Ansfield, M. E., \& Paschall, G. Y. (2002). "You will eat all of that!": a retrospective analysis of forced consumption episodes. Appetite, 38(3), 211-219.

Bevelander, K. E., Anschütz, D. J., Creemers, D. H. M., Kleinjan, M., \& Engels, R. C. M. E. (2013). The role of explicit and implicit self-esteem in peer modeling of palatable food intake: a study on social media interaction among youngsters. PLOS ONE, 8(8), e 72481.

Birch, L. L. (1980). Effects of peer models' food choices and eating behaviors on preschoolers' food preferences. Child Development, 51(2), 489-496.

682

Birch, L. L., \& Deysher, M. (1986). Caloric compensation and sensory specific satiety: evidence for self-regulation of food intake by young children. Appetite, 7, 323-331. 
683

684

685

686

687

688

689

690

691

692

693

694

695

696

697

698

699

700

701

702

703

704

705

706

707

708

709

710

711

712

713

714

715

716

Birch, L. L., \& Fisher, J. O. (1998). Development of eating behaviors among children and adolescents. Pediatrics, 101(3), 539-549.

Birch, L. L., Fisher, J. O., Grimm-Thomas, K., Markey, C. N., Sawyer, R., \& Johnson, S. L. (2001). Confirmatory factor analysis of the Child Feeding Questionnaire: a measure of parental attitudes, beliefs and practices about child feeding and obesity proneness. Appetite, 36, 201-210.

Birch, L. L., Gunder, L., Grimm-Thomas, K., \& Laing, D. G. (1998). Infants' consumption of a new food enhances acceptance of similar foods. Appetite, 30(3), 283-95.

Birch, L. L., Johnson, S. L., Andresen, G., \& Peters, J. C. (1991). The variability of young children's energy intake. The New England Journal of Medicine, 324(4), 232-325.

Birch, L. L., Marlin, D. W., \& Rotter, J. (1984). Eating as the 'means' activity in a contingency: effects on young children's food preference. Child Development, 55(2), 431439.

Birch, L. L., \& Marlin, D. W. (1982). I don't like it; I never tried it: effects of exposure on two-year-old children's food preferences. Appetite, 3(4), 353-360.

Birch, L. L., McPhee, L., Shoba, B. C., Pirok, E., \& Steinberg, L. (1987). What kind of exposure reduces children's food neophobia?: Looking vs. tasting. Appetite, 9(3), 171-178.

Birch, L. L, McPhee L, Steinberg L \& Sullivan S (1990): Conditioned flavor preferences in young children. Physiol. Behav. 47, 501-505.

Birch, L. L., Zimmerman, S. I., \& Hind, H. (1980). The influence of social-affective context on the formation of children's food preferences. Child Development, 51(3), 856-861.

Blissett, J., \& Fogel, A. (2013). Intrinsic and extrinsic influences on children's acceptance of new foods. Physiology and Behaviour, 121, 89-95.

Bovet, D., Vauclair, J., \& Blaye, A. (2005). Categorization and abstraction abilities in 3-year- 
old children: a comparison with monkey data. Animal Cognition, 8(1), 53-59.

Bradbury, J. (2004). Taste perception: cracking the code. Plos Biology, 2(3), 64-64.

720

721

722 723

Brown, S. D. (2010). The rejection of known and previously accepted foods in early childhood. (Doctoral Dissertation). University of Birmingham Research Archive.

Brown, S. D., \& Harris, G. (2012a). Disliked food acting as a contaminant during infancy. A disgust based motivation for rejection. Appetite, 58(2), 535-538.

Brown, S. D., \& Harris, G. (2012b). A theoretical proposal for a perceptually driven, foodbased disgust that can influence food acceptance during early childhood. International Journal of Child Health and Nutrition, 1, 1-10.

Brown, A., \& Lee, M. (2011). Maternal child-feeding style during the weaning period: Association with infant weight and maternal eating style. Eating Behaviors, 12(2), 108111.

Bufe, B., Breslin, P. A. S., Kuhn, C., Reed, D. R., Tharp, C. D., Slack, J. P., ... \& Meyerhof, W. (2005). The molecular basis of individual differences in phenylthiocarbamide and propylthiouracil bitterness perception. Current Biology, 15(4), 322-327.

Bunce, C., \& Gibson, E. L. (2012). Sniffing, eating and disgust in food neophobic children. Appetite, 59(2), 622.

Cambefort, J. P. (1981). A comparative study of culturally transmitted patterns of feeding habits in the chacma baboon Papio ursinus and the vervet monkey Cercopithecus aethiops. Folia Primatologica, 36(3/4), 243-263.

Cain, W. S., \& Stevens, J. C. (1989). Uniformity of olfactory loss in aging. Annals of the New York Academy of Sciences, 561, 29-38.

Carruth, B. R., Skinner, J. D., Houck, K., Moran, J., Coletta, F., \& Ott, D. (1998). The 

phenomenon of "pickyeater": a behavioral marker in eating patterns of toddlers. Journal of the American College of Nutrition, 17, 180-186.

Carruth, B. R., \& Skinner, J. D. (2000). Revisiting the 'picky/fussy' eater phenomenon: neophobic behaviours of young children. Journal of the American College of Nutrition, 19, 771-780.

Carruth, B. R., Ziegler, P. J., Gordon, A., \& Barr, S. I. (2004). Prevalence of picky eaters among infants and toddlers and their caregivers' decisions about offering a new food. Journal of the American Dietetic Association, 104, 57-64.

Casey, R., \& Rozin, P. (1989). Changing children's food preferences: parent opinions. Appetite, 12(3), 171-182.

Cashdan, E. (1994). A sensitive period for learning. Human Nature, 5(3), 279-291.

Cashdan, E. (1998). Adaptiveness of food learning and food aversions in children. Social Science Information, 37(4), 613-632.

Catanzaro, D., Chesbro, E. C., \& Velkey, A. J. (2013). Relationship between food preferences and PROP taster status of college students. Appetite, 68, 124-131.

Clayton, D. A. (1978). Socially facilitated behavior. Quarterly Review of Biology, 53, 373392.

Cooke, L. J., Haworth, C. M., \& Wardle, J. (2007). Genetic and environmental influences on children's food neophobia. American Journal of Clinical Nutrition, 86(2), 428-433.

Cooke, L., Wardle, J., \& Gibson, E. J. (2003). Relationship between parental report of food neophobia and everyday food consumption in 2-6-year-old children. Appetite, 41(2), 205206.

Cooke, L. J., \& Wardle, J. (2005). Age and gender differences in children's food preferences. British Journal of Nutrition, 93(05), 741-746. 
Cowart, B. (1989). Relationships of taste and smell across the adult life span. Annals of the New York Academy of Sciences, 561, 39-55.

Demattè, M. L., Endrizzi, I., Biasioli, F., Corollaro, M. L., Pojer, N., Zampini, M., ... Gasperi, F. (2013). Food neophobia and its relation with olfactory ability in common odour identification. Appetite, 68, 112-117.

Desor, J. A., Maller, O., \& Turner, R. E. (1973). Taste in acceptance of sugars by human infants. Journal of Comparative and Physiological Psychology, 84(3), 496-501.

Dinehart, M. E., Hayes, J. E., Bartoshuk, L. M., Lanier, S. L., \& Duffy, V. B. (2006). Bitter taste markers explain variability in vegetable sweetness, bitterness, and intake. Physiology and Behavior, 87, 304-313.

Dovey, T. M., Staples, P. A, Gibson, E. L., \& Halford, J. C. G. (2008). Food neophobia and "picky/fussy" eating in children: a review. Appetite, 50(2-3), 181-93.

Dovey, T. M., Aldridge, V. K., Dignan, W., Staples, P. A., Gibson, E. L., \& Halford, J. C. G. (2012). Developmental differences in sensory decision making involved in deciding to try a novel fruit. British Journal of Health Psychology, 17(2), 258-272.

Dubois, L., Farmer, A., Girard, M., Peterson, K., \& Tatone-Tokuda, F. (2007). Problem eating behaviors related to social factors and body weight in preschool children: a longitudinal study. International Journal of Behavioral Nutrition and Physical Activity, 4, 9-18.

Faith, M. S., \& Kerns, J. (2005). Infant and child feeding practices and childhood overweight: the role of restriction. Maternal and Child Nutrition, 1(3), 164-168.

Falciglia, G. A., Couch, S. C., Gribble, L. S., Pabst, S. M., \& Frank, R. (2000). Food neophobia in childhood affects dietary variety. Journal of the American Dietetic Association, 100(2), 1474-1481.

Fallon, A. E., Rozin, P., \& Pliner, P. (1984). The child's conception of food: the development of food rejections with special reference to disgust and contamination sensitivity. Child Development, 55(2), 566-575.

Fernández-Ruiz, V., Claret, A., \& Chaya, C. (2013). Testing a Spanish-version of the Food 
807

808

809

810

811

812

813

814

815

816

817

818

819

820

821

822

823

824

825

826

827

828

829

830

831

832

833

834

Flight, I., Leppard, P., \& Cox, D. N. (2003). Food neophobia and associations with cultural diversity and socio-economic status amongst rural and urban Australian adolescents. Appetite, 41(1), 51-59.

Forkman, B. (1991). Social facilitation is shown by gerbils when presented with novel but not with familiar food. Animal Behaviour, 42(5), 860-861.

Galef, B. G., Jr. (1993). Functions of social learning about food: a causal analysis of effects of diet novelty on preference transmission. Animal Behaviour, 46(2), 257-265.

Galloway, A. T., Fiorito, L., Lee, Y., \& Birch, L. L. (2005). Parental pressure, dietary patterns, and weight status among girls who are "picky eaters". Journal of the American Dietetic Association, 105(4), 541-548.

Galloway, A. T., Fiorito, L. M., Francis, L. A., \& Birch, L. L. (2006). "Finish your soup": counterproductive effects of pressuring children to eat on intake and affect. Appetite, 46(3), 318-323.

Galloway, A. T., Lee, Y., \& Birch, L. L. (2003). Predictors and consequences of food neophobia and pickiness in young girls. Journal of the American Dietetic Association, $103(6), 692-698$.

Gerrish, C. J., \& Mennella, J. A. (2001). Flavor variety enhances food acceptance in formulafed infants. The American Journal of Clinical Nutrition, 73, 1080-1085.

Giskes, K., Turnell, G., Patterson, C., \& Newman, B. (2002). Socioeconomic differences among Australian adults in consumption of fruit and vegetables and intakes of vitamins A, C and folate. Journal of Human Nutrition and Dietetics, 15, 375-385.

Harper, L. V., \& Sanders, K. M. (1975). The effect of adult's eating on young children's acceptance of unfamiliar foods. Journal of Experimental Child Psychology, 20, 206-214.

Harris, G. (1993). Introducing the infant's first solid food. British Food Journal, 95(9), 7-10.

Harris, G., Thomas, A., \& Booth, D. A. (1990). Development of salt taste in infancy. 
Havermans, R.C., \& Jansen, A. (2007). Increasing children's liking of vegetables through

Heim, S., Bauer, K. W., Stang, J., \& Ireland, M. (2011). Can a community-based intervention improve the home food environment? Parental perspectives of the influence of the delicious and nutritious garden. Journal of Nutrition Education and Behavior, 43(2), 130-

Hendy, H. M. (2002). Effectiveness of trained peer models to encourage food acceptance in preschool children. Appetite, 39(3), 217-225.

Hendy, H. M., \& Raudenbush, B. (2000). Effectiveness of teacher modeling to encourage 134. food acceptance in preschool children. Appetite, 34(1), 61-76.

Highberger, R., \& Carothers, L. (1977). Modification of eating behavior of toddlers in a day care setting. American Association of Family and Consumer Sciences, 6(1), 48-51.

Hollar, D., Paxton-Aiken, A., \& Fleming, P. (2013). Exploratory validation of the Fruit and Vegetable Neophobia Instrument among third- to fifth-grade students. Appetite, 60, 226230.

Houston-Price, C., Butler, L., \& Shiba, P. (2009). Visual exposure impacts on toddlers' willingness to taste fruits and vegetables. Appetite, 53(3), 450-453.

Jacobi, C., Agras, W. S., Bryson, S., \& Hammer, L. D. (2003). Behavioral validation, precursors, and concomitants of picky eating in childhood. Journal of the American 
Jansen, A. \& Tenney, N. (2001). Seeing Mum drinking a light product: is social learning a stronger determinant of taste preference acquisition than caloric conditioning? European Journal of Clinical Nutrition, 55, 418-422.

Jansen, E., Mulkens, S., \& Jansen, A. (2010). How to promote fruit consumption in children. Visual appeal versus restriction. Appetite, 54(3), 599-602.

Jerzsa-Latta, M., Krondl, M., \& Coleman, P. (1990). Use and perceived attributes of cruciferous vegetables in terms of genetically-mediated taste sensitivity. Appetite, 15(2), $127-134$.

Johnson S, McPhee L \& Birch LL (1991). Conditioned preferences: young children prefer flavors associated with high dietary fat. Physiol. Behav. 50, 1245-1251.

Johnson, C. R., \& Babbitt, R. L. (1993). Antecedent manipulation in the treatment of primary solid food refusal. Behavior Modification, 17(4), 510-521.

Keller, K. L., Steinmann, L., Nurse, R. J., \& Tepper, B. J. (2002). Genetic taste sensitivity to 6-n-propylthiouracil influences food preference and reported intake in preschool children. Appetite, 38, 3-12.

Kern DL, McPhee L, Fisher J, Johnson S \& Birch LL (1993): The postingestive consequences of fat condition preferences for flavors associated with high dietary fat. Physiol. Behav. 54, 71-76.

Kim, U., Jorgenson, E., Coon, H., Leppert, M., Risch, N., \& Drayna, D. (2003). Positional cloning of the human quantitative trait locus underlying taste sensitivity to phenylthiocarbamide. Science, 5610, 1221-1225.

Koivisto-Hursti, U.-K., \& Sjöden, P. (1996). Food and general neophobia in Swedish families: parent-child comparisons and relationships with serving specific foods. Appetite, $26,107-118$. 
897

898

899

900

901

902

903

904

905

906

907

908

909

910

911

912

913

914

915

916

917

918

919

920

921

922

923

924

925

926

927

928

Koivisto-Hursti, U.-K., \& Sjöden, P. (1997). Food and general neophobia and their relationship with self-reported food choice: familial resemblance in Swedish families with children of ages 7-17 years. Appetite, 29, 89-103.

Laureati, M., Bergamaschi, V., \& Pagliarini, E. (2014). School-based intervention with children. Peer-modeling, reward and repeated exposure reduce food neophobia and increase liking of fruits and vegetables. Appetite, 83, 26-32.

Laureati, M., Bergamaschi, V., \& Pagliarini, E. (2015). Assessing childhood food neophobia: validation of a scale in Italian primary school children. Food Quality and Preference, 40, 8-15.

Lavin, T. A., \& Hall, D. G. (2001). Domain effects in lexical development: learning words for foods and toys. Cognitive Development, 16(4), 929-950.

Lien, N., Jacobs, D. R., Jr., \& Klepp, K.-I. (2002). Exploring predictors of eating behaviour among adolescents by gender and socio-economic status. Public Health Nutrition, 5(5), 671-681.

Loewen, R., \& Pliner, P. (2000). The Food Situations Questionnaire: a measure of children's willingness to try novel foods in stimulating and non-stimulating situations. Appetite, 35(3), 239-250.

Lumeng, J. C. (2013). Food as a unique domain of social cognition. In M. R. Banaji \& S. A. Gelman (Eds.), Navigating the social world (pp. 245-249). Oxford University Press.

Lumeng, J. C., Patil, N., \& Blass, E. M. (2007). Social influences on formula intake via suckling in 7 to 14-week-old-infants. Developmental Psychobiology, 49(4), 351-361.

Macario, J. F. (1991). Young children's use of color in classification: foods and canonically colored objects. Cognitive Development, 6(1), 17-46.

Marchi, M., \& Cohen, P. (1990). Early childhood eating behaviors and adolescent eating disorders. Journal of the American Academy of Child and Adolescent Psychiatry, 29, 112117. 
930 Marcontell, D. K., Laster, A. E., \& Johnson, J. (2003). Cognitive-behavioral treatment of food neophobia in adults. Journal of Anxiety Disorders, 17(2), 243-251.

Martins, Y., Pelchat, M. L., \& Pliner, P. (1997). "Try it; it's good and it's good for you": effects of taste and nutrition information on willingness to try novel foods. Appetite, 28(2), 89-102.

Martins, Y., \& Pliner, P. (2005). Human food choices: an examination of the factors underlying acceptance / rejection of novel and familiar animal and nonanimal foods. Appetite, 45(3), 214-224.

Martins, Y., \& Pliner, P. (2006). “Ugh! That's disgusting!”: identification of the characteristics of foods underlying rejections based on disgust. Appetite, 46(1), 75-85.

Mascola, A. J., Bryson, S. W., \& Agras, W. S. (2010). Picky eating during childhood: A longitudinal study to age 11 years. Eating Behaviors, 11(4), 253-257.

Mattes, R., \& Labov, J. (1989). Bitter taste responses to phenylthiocarbamide are not related to dietary goitrogen intake in human beings. Journal of the American Dietetic Association, 89(5), 692-694.

McFarlane, T., \& Pliner, P. (1997). Increasing willingness to taste novel foods: effects of nutrition and taste information. Appetite, 28(3), 227-38.

McNicol, S. A. M., Murray, S. M., \& Austin, E. J. (2003). Relationships between personality, attitudes and dietary behaviour in a group of Scottish adolescents. Personality and Individual Differences, 35(8), 1753-1764.

Mennella, J. A., \& Beauchamp, G. K. (1999). Experience with a flavor in mother's milk modifies the infant's acceptance of flavored cereal. Developmental Psychobiology, 35(3), 197-203.

Mennella, J. A., Jagnow, C. P., \& Beauchamp, G. K. (2001). Prenatal and postnatal flavor learning by human infants. Pediatrics, 107(6), 88-99. 
960 Mennella, J. A., Nicklaus, S., Jagolino, A. L., \& Yourshaw, L. M. (2008). Variety is the spice 961 of life: strategies for promoting fruit and vegetable acceptance during infancy. Physiology

Milton, K. (1993). Diet and primate evolution. Scientific American, 269, 70-77.

964

965

966

967

968

969

970

971

972

973

974

975

976

977

978

979

980

981

982

983

984

985

986

Murphy, C. (1985). Cognitive and chemosensory influences on age related changes in the ability to identify blended foods. Journal of Gerontology, 40, 47-52.

Nederkoorn, C., Jansen, A., \& Havermans, R. C. (2015). Feel your food. The influence of tactile sensitivity on picky eating in children. Appetite, 84, 7-10.

Nguyen, S. P., \& Murphy, G. L. (2003). An apple is more than just a fruit: cross-classification in children's concepts. Child Development, 74(6), 1783-1806.

Nicholls, D., Christie, D., Randall, L., \& Lask, B. (2001). Selective eating: symptom, disorder or normal variant. Clinical child psychology and psychiatry, 6(2), 257-270.

Nicklaus, S. (2009). Development of food variety in children. Appetite, 52(1), 253-255.

Nicklaus, S., Boggio, V., Chabanet, C., \& Issanchou, S. (2005). A prospective study of food variety seeking in childhood, adolescence and early adult life. Appetite, 44(3), 289-297.

Nordin, S., Broman, D. A., Garvill, J., \& Nyroos, M. (2004). Gender differences in factors affecting rejection of food in healthy young Swedish adults. Appetite, 43(3), 295-301.

Nosofsky, R. M. (1992). Exemplar-based approach to relating categorization, identification, and recognition. In F. G. Ashby (Ed.), Multidimensional models of perception and cognition. Scientific psychology series (pp. 363-393). Hillsdale, NJ, England: Lawrence Erlbaum Associates, Inc.

Olsen, A., Ritz, C., Kramer, L., Møller, P. Serving styles of raw snack vegetables What do children want? Appetite, 59(2), 556-562. 
987

988

989

990

991

992

993

994

995

996

997

998

999

1000

1001

1002

1003

1004

1005

1006

1007

1008

1009

1010

1011

1012

1013

Pelchat, M. L. (2000). You can teach an old dog new tricks: olfaction and responses to novel foods by the elderly. Appetite, 35(2), 153-160.

Pelchat, M. L., \& Pliner, P. (1986). Antecedents and correlates of feeding problems in young children. Journal of Nutrition Education, 18(1), 153-165.

Pelchat, M. L., \& Pliner, P. (1995). “Try it. You'll like it.” Effects of information on willingness to try novel foods. Appetite, 24, 153-165.

Pliner, P. (1982). The effects of mere exposure on liking for edible substances. Appetite, 3, 283-290.

Pliner, P. (1994). Development of measures of food neophobia in children. Appetite, 23, $147-$ 163.

Pliner, P., Eng, A., \& Krishnan, K. (1995). The effects of fear and hunger on food neophobia in humans. Appetite, 25, 77-87.

Pliner, P., \& Hobden, K. (1992). Development of a scale to measure the trait of food neophobia in humans. Appetite, 19(2), 105-120.

Pliner, P., \& Melo, N. (1997). Food neophobia in humans: effects of manipulated arousal and individual differences in sensation seeking. Physiology and Behavior, 61(2), 331-335.

Pliner, P., Pelchat, M., Grabski, M. (1993). Reduction of neophobia in humans by exposure to novel foods. Appetite, 20, 111-123.

Potts, H. W. W., \& Wardle, J. (1998). The list heuristic for studying personality correlates of food choice behaviour: a review and results from two samples. Appetite, 30, 79-92.

Raudenbush, B., \& Capiola, A. (2012). Physiological responses of food neophobics and food neophilics to food and non-food stimuli. Appetite, 58(3), 1106-1108.

Raudenbush, B., Corley, N., Flower, N. R., Kozlowski, A., \& Meyer, B. (2003). Cephalic phase salivary response differences characterize level of food neophobia. Appetite, 41(2), 211-212. 
1014 Raudenbush, B., Schroth, F., Reilley, S., \& Frank, R. A. (1998). Food neophobia, odor 1015 evaluation and exploratory sniffing behavior. Appetite, 31, 171-183.

1016 Raudenbush, B., Van Der Klaauw, N. J., \& Frank, R. A. (1995). The contribution of 1017 psychological and sensory factors to food preference patterns as measured by the Food 1018 Attitudes Survey (FAS). Appetite, 25(1), 1-15.

1019 Raynor, H. A., \& Epstein, L. H. (2001). Dietary variety, energy regulation, and obesity. $1020 \quad$ Psychological Bulletin, 127(3), 325-341.

1021 Reverdy, C., Chesnel, F., Schlich, P., Köster, E. P., \& Lange, C. (2008). Effect of sensory 1022 education on willingness to taste novel food in children. Appetite, 51(1), 156-165.

1023 Rigal, N., Chabanet, C., Issanchou, S., \& Monnery-Patris, S. (2012). Links between maternal 1024 feeding practices and children's eating difficulties. Validation of French tools. Appetite, $1025 \quad 58(2), 629-637$.

1026

1027

Rigal, N., Frelut, M., Monneuse, M., \& Hladik, C. (2006). Food neophobia in the context of a 1028 1029 varied diet induced by a weight reduction program in massively obese adolescents. Appetite, 46(2), 207-214.

1030 Rolls, B. J. (1986). Sensory-specific satiety. Nutrition Reviews, 44 (3), 93-101.

Rolls, E. T., \& Rolls, J. H. (1997). Olfactory sensory-specific satiety in humans. Physiology and Behavior, 61(3), 461-473.

1034

1035

1036

1037

1038

1039

Rosenstein, D., \& Oster, H. (1988). Differential facial responses to four basic tastes in newborns. Child Development, 59, 1555-1568.

Rosen, A. B., \& Rozin, P. (1993). Now you see it, now you don't: the preschool child's conception of invisible particles in the context of dissolving. Developmental Psychology, 29(2), 300-311.

Rozin, P. (1977). The use of characteristic flavorings in human culinary practice. In C. M. Apt (Ed.), Flavor: its chemical, behavioural, and commercial aspects (pp. 101-127). 
Rozin, P. (1979). Preference and affect in food selection. In J. H. A. Kroeze (Ed.), Preference, Behaviour \& Chemoreception (pp. 289-297). London: Information Retrieval Limited.

Royeen, C. B. (1986). The development of a touch scale for measuring tactile defensiveness in children. The American Journal of Occupational Therapy, 40(6), 414-419.

Rozin, P., Hammer, L., Oster, H., Horowitz, T., \& Marmora, V. (1986). The child's conception of food: differentiation of categories of rejected substances in the 16 months to 5 year age range. Appetite, 7, 141-151.

Rozin, P., Millman, L., \& Nemeroff, C. (1986). Operation of the laws of sympathetic magic in disgust and other domains. Journal of Personality and Social Psychology, 50(4), 703-712.

Rozin, P., \& Vollmecke, T. (1986). Food likes and dislikes. Annual Review of Nutrition, 6, 433-456.

Rubio, B., Rigal, N., Boireau-Ducept, N., Mallet, P., \& Meyer, T. (2008). Measuring willingness to try new foods: a self-report questionnaire for French-speaking children. Appetite, 50(2-3), 408-414.

1061

Rydell, A.-M., Dahl, M. \& Sundelin, C. (1995). Characteristics of school children who are choosy eaters. The Journal of Genetic Psychology: Research and Theory on Human Development, 156(2), 217-299.

Salvy, S. J., Vartanian, L. R., Coelho, J. S., Jarrin, D., \& Pliner, P. P. (2008). The role of familiarity on modeling of eating and food consumption in children. Appetite, 50(2-3),

Santos, L. R., Hauser, M. D., \& Spelke, E. S. (2002). Domain-specific knowledge in human 514-518. children and non-human primates: artifact and food kinds. In M. Bekoff (Ed.), The Cognitive Animal (pp. 205-215). Cambridge, MA: MIT Press.

Shore, B. A., Babbitt, R. L., Williams, K. E., Coe, D. A., \& Snyder, A. (1998). Use of texture 
1075

1076

1077

1078

1079

1080

1081

1082

1083

1084

1085

1086

1087

1088

1089

1090

1091

1092

1093

1094

1095

1096

1097

1098

1099

1100

1101

1102

1103

1104

1105

fading in the treatment of food selectivity. Journal of Applied Behavior Analysis, 31(4), 621-633.

Shutts, K., Condry, K. F., Santos, L. R., \& Spelke, E. S. (2009). Core knowledge and its limits: the domain of food. Cognition, 112(1), 120-40.

Shutts, K., Kinzler, K. D., \& Dejesus, J. M. (2013). Understanding infants' and children's social learning about foods: previous research and new prospects. Developmental Psychology, 49(3), 419-425.

Shutts, K., Kinzler, K. D., McKee, C. B., \& Spelke, E. S. (2009). Social information guides infants' selection of foods. Journal of Cognition and Development, 10(1-2), 1-17.

Siegal, M. (1988). Children's knowledge of contagion and contamination as causes of illness. Child Development, 59(5), 1353-1359.

Singer, L. T., Ambuel, B., Wade, S., \& Jaffe, A. C. (1992) Cognitive-behavioral treatment of health-impairing food phobias in children. Journal of the American Academy of Child and Adolescent Psychiatry, 31(5), 847-852.

Skinner, J. D., \& Carruth, B. R. (2002). Do food-related experiences in the first 2 years of life predict dietary variety in school-aged children? Journal of Nutrition Education and Behavior, 34(6), 310-315.

Slatterey, M. L., Benson, J., Curtin, K., Ma, K. N., Schaeffer, D., \& Potter, J. D. (2000). American Journal of Clinical Nutrition, 71(2), 575-582.

Smith, A. M., Roux, S., Naidoo, N. T., \& Venter, D. J. L. (2005). Food choices of tactile defensive children. Nutrition, 21(1), 14-19.

Springer, K., \& Belk, A. (1994). The role of physical contact and association in early contamination sensitivity. Developmental Psychology, 30(6), 864-868.

Stein, A. (1973). Middle school no. 26, Peking, China. Equity and Excellence in Education, $11(2), 15-21$. 
Story, M., \& Brown, J. E. (1987). Do young children instinctively know what to eat? The studies of Clara Davis revisited. The New England Journal of Medicine, 316(2), 103-106.

Sullivan, S. A., \& Birch, L. L. (1994). Infant dietary experience and acceptance of solid foods. Pediatrics, 93(2), 271-277.

Taveras, E. M., Scanlon, K. S., Birch, L., Rifas-Shiman, S. L., Rich-Edwards, J. W., \& Gillman, M. W. (2004). Association of breastfeeding with maternal control of infant feeding at age 1 year. Pediatrics, 114(5), 577-583.

1116

Temple, J. L., Chappel, A., Shalik, J., Volcy, S., \& Epstein, L. H. (2008). Daily consumption of individual snack foods decreases their reinforcing value. Eating Behaviors, 9(3), 267276.

Tharner, A., Jansen, P. W., Kiefte-de Jong, J. C., Moll, H. A., van der Ende, J., Jaddoe, V. W., ... Franco, O. H. (2014). Toward an operative diagnosis of fussy/picky eating: a latent profile approach in a population-based cohort. International Journal of Behavioral Nutrition and Physical Activity, 11(1), 14-24.

Tomasello, M., \& Call, J. (1997). Primate cognition. New York: Oxford University Press.

Ton Nu, C., MacLeod, P., \& Barthelemy, J. (1996) Effects of age and gender on adolescents' food habits and preferences. Food Quality and Preference, 7, 251- 262.

Toyama, N. (1999). Developmental changes in the basis of associational contamination thinking. Cognitive Development, 14(2), 343-361.

Toyama, N. (2000). Young children's awareness of socially mediated rejection of food: why is food dropped at the table "dirty"? Cognitive Development, 15(4), 523-541. related responses to familiar and unfamiliar foods. Food Quality and Preference, 12(1), 29-37. 
1139

1140

1141

1142

1143

1144

1145

1146

1147

1148

1149

1150

1151

1152

1153

1154

1155

1156

1157

1158

1159

1160

1161

1162

1163

1164

1165

1166

1167

Van der Horst, K. (2012). Overcoming picky eating. Eating enjoyment as a central aspect of children's eating behaviors. Appetite, 58(2), 567-574.

Van Duyn, M. A. S., \& Pivonka, E. (2000). Overview of the health benefits of fruit and vegetable consumption for the dietetics professional: selected literature. Journal of the American Dietetic Association, 100(12), 1511-1521.

Vereecken, C. A., Keukelier, E., \& Maes, L. (2004). Influence of mother's educational level on food parenting practices and food habits of young children. Appetite, 43(1), 93-103.

Visalberghi, E., \& Addessi, E. (2000). Seeing group members eating a familiar food enhances the acceptance of novel foods in capuchin monkeys. Animal Behaviour, 60(1), 69-76.

Visalberghi, E., \& Fragaszy, D. M. (1990). Food-washing behaviour in tufted capuchin monkeys, Cebus apella, and crabeating macaques, Macaca fascicularis. Animal Behaviour, $40(5), 829-836$.

Visalberghi, E., \& Fragaszy, D. M. (1995). The behavior of capuchin monkeys, Cebus appella, with novel food: the role of social context. Animal Behaviour, 49, 1089-1095.

Visalberghi, E., \& Fragaszy, D. M. (2002). “Do monkeys ape?”-Ten years after. In K.

Dautenhahn, \& C. L. Nehaniv (Eds.), Imitation in animals and artifacts (pp. 471-499). Cambridge, MA: MIT Press.

Vitale, A., \& Queyras, A. (1997). The response to novel foods in common marmoset (Callithrix jacchus): the effects of different social contexts. Ethology, 103(5), 395-403.

Voelkl, B., Schrauf, C., \& Huber, L. (2006). Social contact influences the response of infant marmosets towards novel food. Animal Behaviour, 72(2), 365-372.

Wadhera, D., \& Capaldi-Phillips, E. D. (2014). A review of visual cues associated with food on food acceptance and consumption. Eating Behaviors, 15(1), 132-143. 
1168 Wardle, J., Carnell, S., \& Cooke, L. (2005). Parental control over feeding and children's fruit and vegetable intake: how are they related? Journal of the American Dietetic Association, 105(2), 227-232.

1171 Wardle, J., \& Cooke, L. (2008). Genetic and environmental determinants of children's food preferences. British Journal of Nutrition, 99(1), 15-21.

Wardle, J., Herrera, M. L., Cooke, L., \& Gibson, E. L. (2003). Modifying children's food preferences: the effects of exposure and reward on acceptance of an unfamiliar vegetable. European Journal of Clinical Nutrition, 57(2), 341-348.

Wardle, J., Guthrie, C. A., Sanderson, S., \& Rapoport, L. (2001). Development of the Children's Eating Behaviour Questionnaire. Journal of Child Psychology and Psychiatry, 42(7), 963-970.

Webber, L., Cooke, L., Hill, C., \& Wardle, J. (2010). Associations between children's appetitive traits and maternal feeding practices. Journal of the American Dietetic Association, 110(11), 1718-1722.

Weiskrantz, L., \& Cowey, A. (1963). The aetiology of food reward in monkeys. Animal Behavior, 11(2-3), 225-234.

Whiten, A., \& Ham, R. (1992). On the nature and evolution of imitation in the animal kingdom: reappraisal of a century of research. Advances in the Study of Behavior, 21, 239-

Wilbarger, P. (2000). Sensory defensiveness and related social/emotional and neurological disorders. Port Elizabeth, South Africa: Publisher. of children: the importance of presentation on desire for diversity. Acta Paediatrica, 101(1), 61-66. Lawrence Erbaum Associates. 